\title{
Distribution System Reliability Analysis for Smart Grid Applications
}

\author{
Tawfiq M. Aljohani*, Mohammed J. Beshir \\ Ming Hsieh Department of Electrical Engineering, University of Southern California, Los Angeles, USA \\ Email: ^aljohani@usc.edu, Beshir@usc.edu
}

How to cite this paper: Aljohani, T.M. and Beshir, M.J. (2017) Distribution System Reliability Analysis for Smart Grid Applications. Smart Grid and Renewable Energy, 8, 240-251.

https://doi.org/10.4236/sgre.2017.87016

Received: May 26, 2017

Accepted: July 3, 2017

Published: July 6, 2017

Copyright $\odot 2017$ by authors and Scientific Research Publishing Inc. This work is licensed under the Creative Commons Attribution International License (CC BY 4.0).

http://creativecommons.org/licenses/by/4.0/

(c) (i) Open Access

\begin{abstract}
Reliability of power systems is a key aspect in modern power system planning, design, and operation. The ascendance of the smart grid concept has provided high hopes of developing an intelligent network that is capable of being a self-healing grid, offering the ability to overcome the interruption problems that face the utility and cost it tens of millions in repair and loss. In this work, we will examine the effect of the smart grid applications in improving the reliability of the power distribution networks. The test system used in this paper is the IEEE 34 node test feeder, released in 2003 by the Distribution System Analysis Subcommittee of the IEEE Power Engineering Society. The objective is to analyze the feeder for the optimal placement of the automatic switching devices and quantify their proper installation based on the performance of the distribution system. The measures will be the changes in the reliability system indices including SAIDI, SAIFI, and EUE. In addition, the goal is to design and simulate the effect of the installation of the Distributed Generators (DGs) on the utility's distribution system and measure the potential improvement of its reliability.
\end{abstract}

\section{Keywords}

Power System Reliability, Smart Grid Applications, Distribution System Reliability, Automatic Reclosers, Distributed Generation, Self-Healing Power Grids

\section{Introduction}

Power system reliability is a key aspect in power distribution system planning, design, and operation. Electric power utilities are required to provide uninterrupted electrical services to their customers at the lowest possible cost while maintaining an acceptable level of service quality. The importance of reliability arises as it can express the cost of service outages. A distribution system's quality 
of service can be judged by its reliability indices, which can be increased by automation of its feeder and associated parts, which eventually will lead to a desired reduction in the power interruptions. Reliable power distribution networks are those managing a high level of reliability.

The traditional power distribution grid is radial in nature, the power flows in one direction from the distribution substation to the load point. The radial system has low reliability, and those customers who are located at the end of the circuit, tend to be more prone to power outages than any other customers. Since there are no backup or alternative sources to back up the traditional distribution systems, there is a high chance that a major fault on the feeder would affect a substantial number of customers in the radial configuration [1] [2] [3] [4].

The concept of reliability can be simply expressed as two states or conditions: up and down. The first, up, would mean that the system is available (functioning) while the latter, down, means the system is unavailable (failing). Electrically, when a device is interrupted by a fault, the state or condition of this specific equipment would be adjusted from the up state to the down state. The down state lasts until the equipment is fully repaired. Once the equipment goes alive with the grid, the state condition returns to the up state again. The reliability problem could become even worse if the failure of one component influences the failure of others, increasing the possibility of cascading outages [5] [6]. The development of smart grid has raised questions recently about the opportunities this new technology offers to enhance the reliability of electric service. The term "smart grid" refers to the modernization of the electric power grid via the application of information and communication systems to incorporate alternative sources of energy into the power grid [7].

\section{Literature Review}

There have been considerable volumes of research to quantify the benefits that can arise from the integration of the smart grid applications into the enhancement of the reliability of the power distribution grids. The U.S. Department of Energy states [2]:

Think of the smart grid as the internet brought to our electric system. Devices such as wind turbines, plug-in hybrid electric vehicles, and solar arrays are not part of the smart grid. Rather, the smart grid encompasses the technology that enables us to integrate, interface, with intelligently control these innovations and others.

Many efforts have been made to quantify the losses of the utilities due to the faults and outages in the distribution grid. Furthermore, there have been suggestions that many inconsistencies are found in the reported collected data that measure the utilities interruption events and its reliability indices' performance. Reference [8] suggested organization of the data used to make a comparison of distribution system reliability performances.

References [9] [10] discuss the concept of microgrids and the idea that microgrids can contribute effectively in the implementation of many smart grid func- 
tions, such as enhancing the reliability of the distribution grid and applying the concept of a self-supporting network. It suggested that the focus of improvements in the upcoming years would be in the distribution sector of the power systems, with no major changes applied to the power system's transmission system. For example, incentives related to renewable energy are going to strengthen the desire of utilities and academia to conduct research on the distribution grids. [9] argues that by bringing power sources closer to load centers, the electric infrastructure will experience tremendous enhancements in voltage profile, minimizing both transmission and distribution losses, and enhancing the use of heat by exploiting wasted heat from conventional DGs.

\section{Case Studies}

\section{Case Study 1: The Reliability Impact of the Optimal Placement of Automatic Reclosers.}

In this paper, we analyze the potential effect of optimal installation of automatic reclosers on the distribution feeders, using the analytical technique. The application on this analysis is done using DISREL, an intelligent software that uses the concept of brute force in analyzing test systems, quantifies the effects of modifications, and provides recommendations for optimal installation of switches. Failure rates and MTTR values that have been used in modelling the original IEEE 34-node feeder in this work are based on the average values obtained from reference [1]. The automatic recloser (AR) is a protection device that has the ability to detect a fault and open for a pre-programmed time before closing again automatically and without the interference of the human factor. If optimally installed, ARs can help in achieving the concept of a self-healing power grid, which is one of the smart grid's main concepts according to the U.S. department of energy. It should be noted that several studies have been conducted to examine the effect of both optimal configuration and automatic switches on the distribution grid in the smart era and measure virtues of several scenarios [11] [12] [13]. In this work, we first model the original IEEE 34-node feeder using DISREL. Table 1 shows the results of the software recommendations for the optimal installations of automatic reclosers. The base case in this study is the original IEEE 34-node test system. Any contingency event will result in the loss of all the customers in service. SAIDI, SAIFI and other indices are simulated and provided in Table 1 for the original feeder following any outage event and before install any sectionalizing devices. Reference [14] discusses in detail an algorithm, developed by the authors of this paper, which is based on the analytical technique. The algorithm illustrates the main concepts of the isolation and restoration process in the distribution grid when installing automatic reclosers or switches. This is done by coordinating the MTTS of the automatic reclosers to be the time reclosers would take to locate the nearest sectionalizing devices. The provided results by the software suggest that the optimal location to install the automatic recloser is between nodes 832-858. Furthermore, it is shown that SAIDI has been reduced from 927.25 to 840.83 minutes per year, indicating an 
Table 1. The results for the optimal placements of the reclosers and switches.

\begin{tabular}{ccccccc}
\hline Case Description & SAIFI & SAIDI & CAIDI & ASAI & $\begin{array}{c}\text { EUE } \\
(\mathrm{kW} / \mathrm{yr})\end{array}$ & Outage Cost (\$) \\
\hline Base Case & 5.35187 & 927.25385 & 173.25789 & 0.998235822 & 25,245 & $251,769.00$ \\
Add AR [832-858] & 4.91459 & 840.828 & 171.088 & 0.998400271 & 22,888 & $228,293.00$ \\
Add AR [858-834] & 4.87825 & 848.89636 & 174.01645 & 0.998384893 & 23,109 & $230,501.00$ \\
Add AR [834-860] & 4.84965 & 865.86755 & 178.54211 & 0.998352587 & 23,572 & $235,100.00$ \\
Add AR [860-836] & 4.90973 & 873.88715 & 177.99095 & 0.998337328 & 23,791 & $237,276.00$ \\
Add AR [834-842] & 5.08451 & 886.42841 & 174.33902 & 0.998313487 & 24,134 & $240,694.00$ \\
\hline
\end{tabular}

average of $9.32 \%$ reduction, or in other words improvement, to the duration of interruptions that the average customer will experience over the course of a year. This will allow the utility to improve its service to the customer, in case of a fault occurring downstream of the automatic recloser installed on this specific location. The recloser would automatically isolate the affected area of the feeder; thus, restoring the service to the upstream customers, which improves SAIDI in this case. However, if the fault is located upstream of the automatic recloser, then there is no way to restore the power to the downstream customer unless there is another source of power that can feed these customers while isolating this fault when possible. This will give virtues to the utilities in reducing the repair hours by detecting the location of the fault quicker than the case of the original feeder, where there is no sectionalizing switch at all.

Yet, this does not necessarily mean that this option will yield the best outcomes in regard to SAIFI. SAIFI measures the sustained interruptions an average customer will experience. For the best option provided by the software, which is installing the automatic recloser in between 832-858, SAIFI also witnessed a reduction from 5.35 to 4.92 interruptions per customer over the course of a year, which is equal to $8.16 \%$ improvements, while in some other options results in greater reduction $(9.34 \%$ when install the auto-recloser in between $858-834$ instead, as shown in Figure 1). However, it is expected that installing another automatic sectionalizing device would yield better improvements and savings to the system.

To investigate such option, wemodify the test system to include the first recloser as DISREL suggests in between 832-858 and then model it to examine the effect of adding other automatic sectionalizing devices on the grid. Table 2 shows the results of the modified IEEE test system shown in Figure 2. Based on the results, the installation of two automatic reclosers projects more improvement to the system indices, with higher revenues. The simulated results suggest that installing the recloser at $834-860$ will raise a total savings of $\$ 34,112$. This can be justified by the fact that the utility would be able to isolate faults that are probably located near the densest area in the feeder, where around $40 \%$ of the total load is located in the distance between 858 to the end of the lateral at 848 . In addition, this would reduce the repair hours for the utilities to fix the issues as 


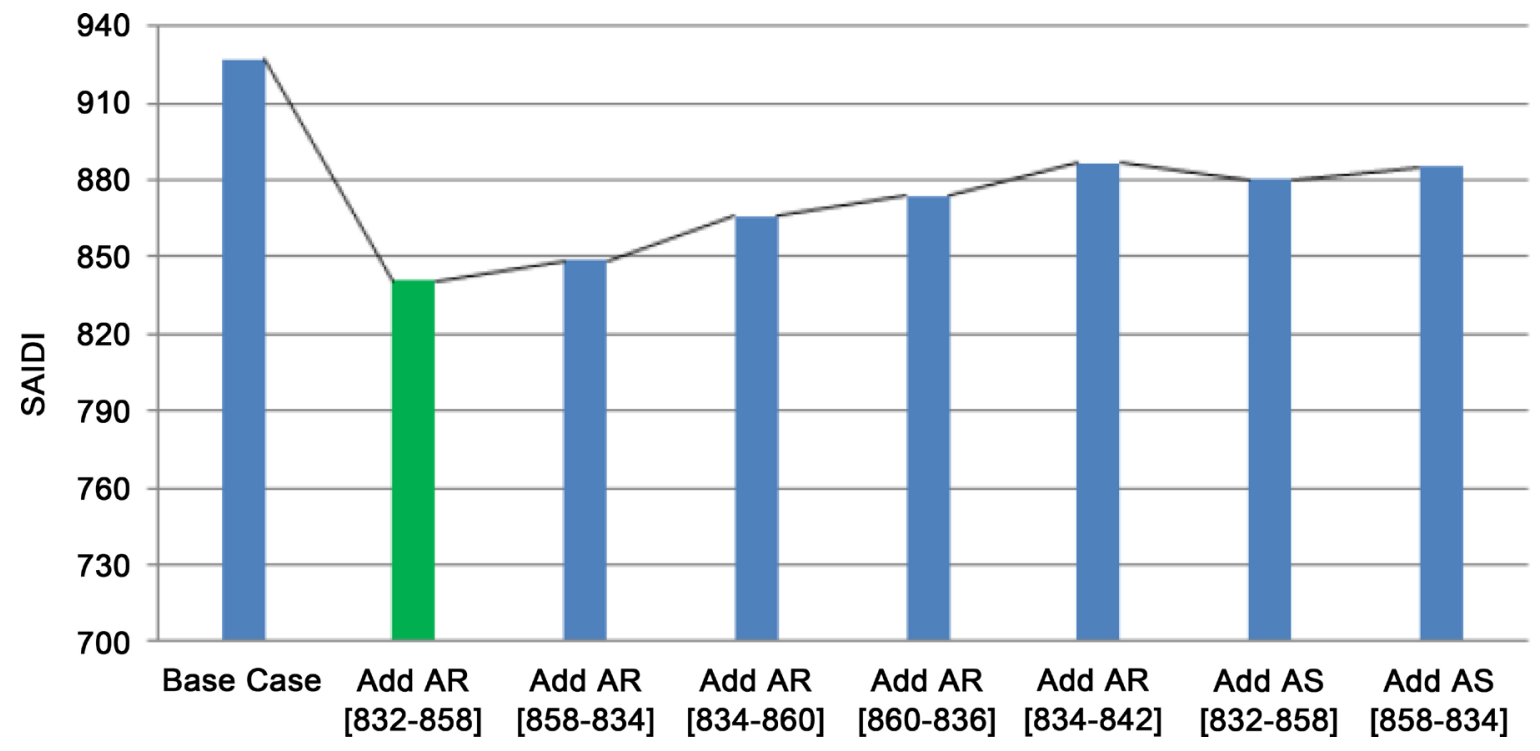

Figure 1. Around 10\% improvements in SAIDI considering one AR.

Table 2. The results of the optimal placements for the modified test feeder shown in Figure 2.

\begin{tabular}{ccccccc}
\hline Case Description & SAIFI & SAIDI & CAIDI & ASAI & EUE (kW) & Outage Cost (\$) \\
\hline Base Case & 5.35187 & 927.25385 & 173.25789 & 0.998235822 & 25,245 & $251,769.00$ \\
Base Case + one AR & 4.94058 & 833.42004 & 168.68883 & 0.998414338 & 22,686 & $226,282.00$ \\
Add AR [834-860] & 4.66379 & 801.66541 & 171.89131 & 0.998474777 & 21,822 & $217,657.00$ \\
Add AR [860-836] & 4.69352 & 804.74646 & 171.45895 & 0.998468876 & 21,906 & $218,496.00$ \\
Add AR [834-842] & 4.78457 & 817.78149 & 170.92068 & 0.99844408 & 22,262 & $222,051.00$ \\
Add AR [832-888] & 4.79635 & 816.11261 & 170.15291 & 0.998447299 & 22,213 & $221,571.00$ \\
Add AR [842-844] & 4.85976 & 825.29413 & 169.82184 & 0.998429835 & 22,465 & $224,082.00$ \\
Add AS [834-860] & 5.32914 & 812.24915 & 152.41666 & 0.99845463 & 22,110 & $220,465.00$ \\
Add AS [860-836] & 5.39499 & 816.2149 & 151.29141 & 0.998447061 & 22,218 & $221,545.00$ \\
\hline
\end{tabular}

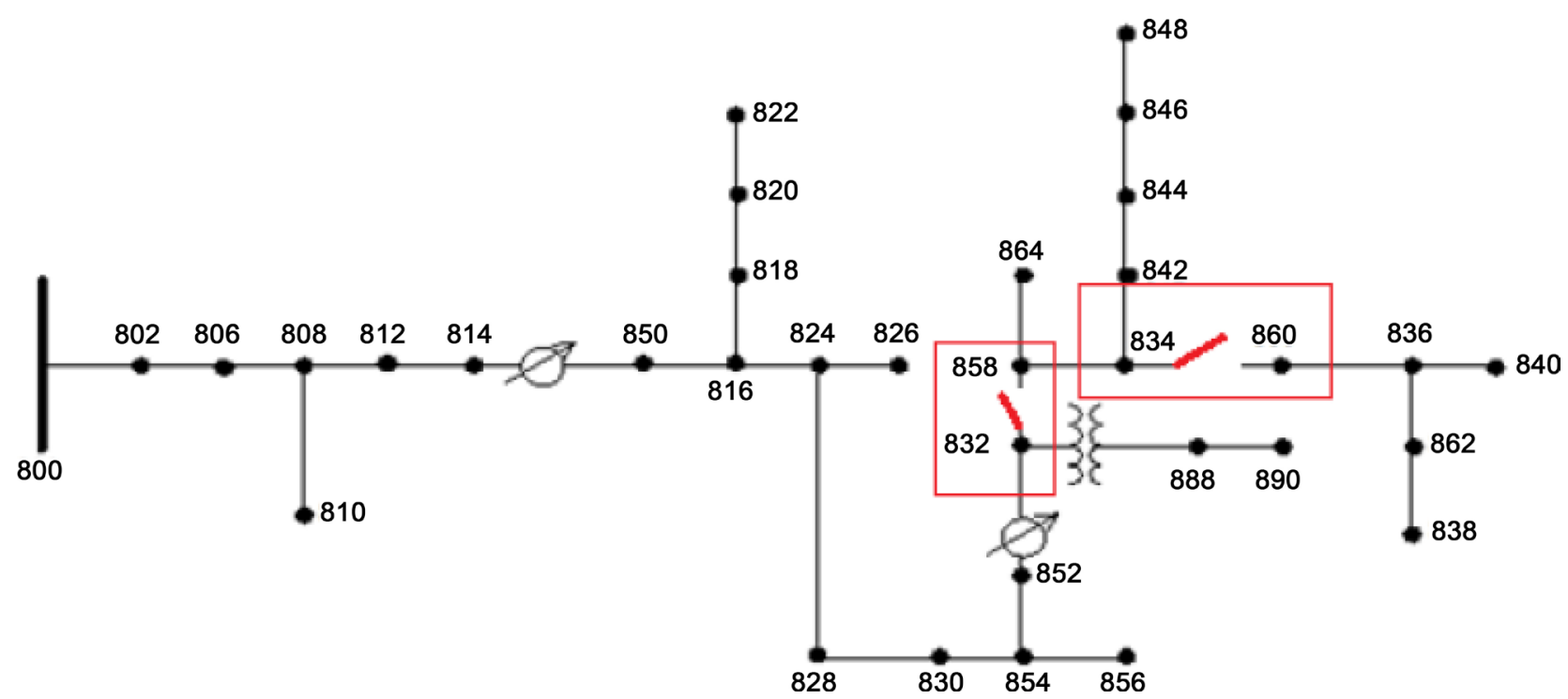

Figure 2. The optimal locations of ARs based on the results. 
fast as possible and restore the power more quickly in the areas where the customers are still experiencing service interruption. An outage would make the automatic recloser opens to isolate and clear the fault. If the customers who are upstream of the automatic recloser (located between 832-858) are still out of service after isolating the fault, then mostly the fault will be located in the area upstream this recloser to the distribution substation.

This concept can be applied to all the automatic reclosers (or switches) until the location of the fault is detected, which would reduce the repair hours, thus improving SAIDI index. The installation of these two automatic devices is considered the optimal solution in this case, since it both reduces SAIFI and SAIFI by $12.9 \%$ and $13.54 \%$ respectively. Figure 3 shows the projected savings for considering two sectionalizing devices, while Figure 4 shows a multi-scale graph comparing the savings to the outage costs for this case. It can be shown that when we install a second AR at 834-860, the system achieves the highest savings

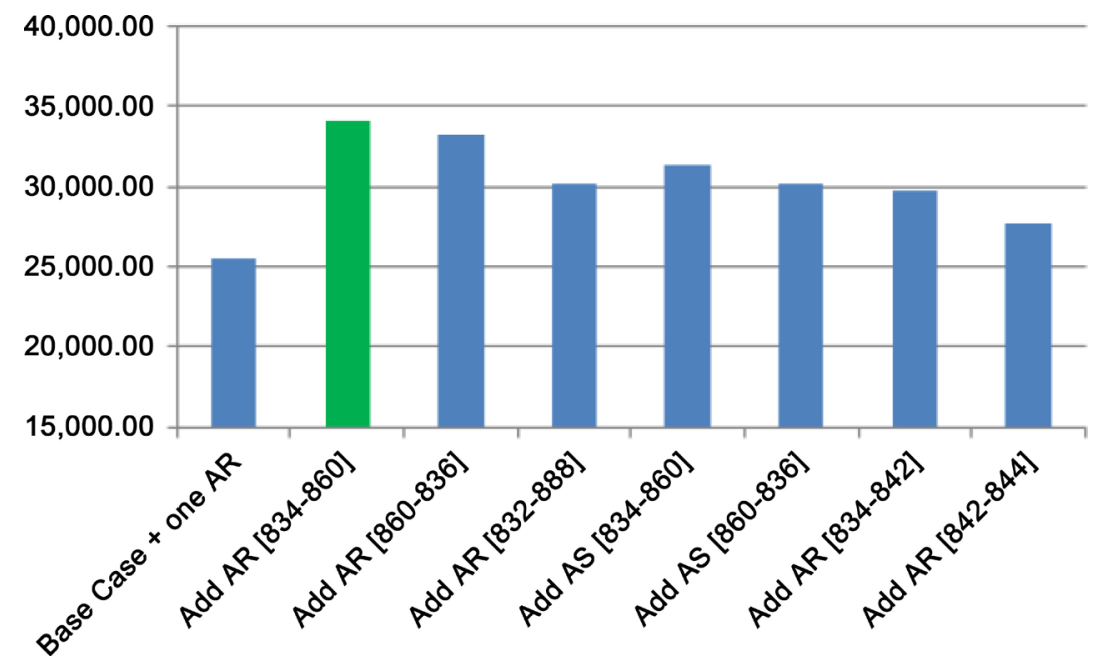

Figure 3. Projected savings for case study 1 considering two ARs.

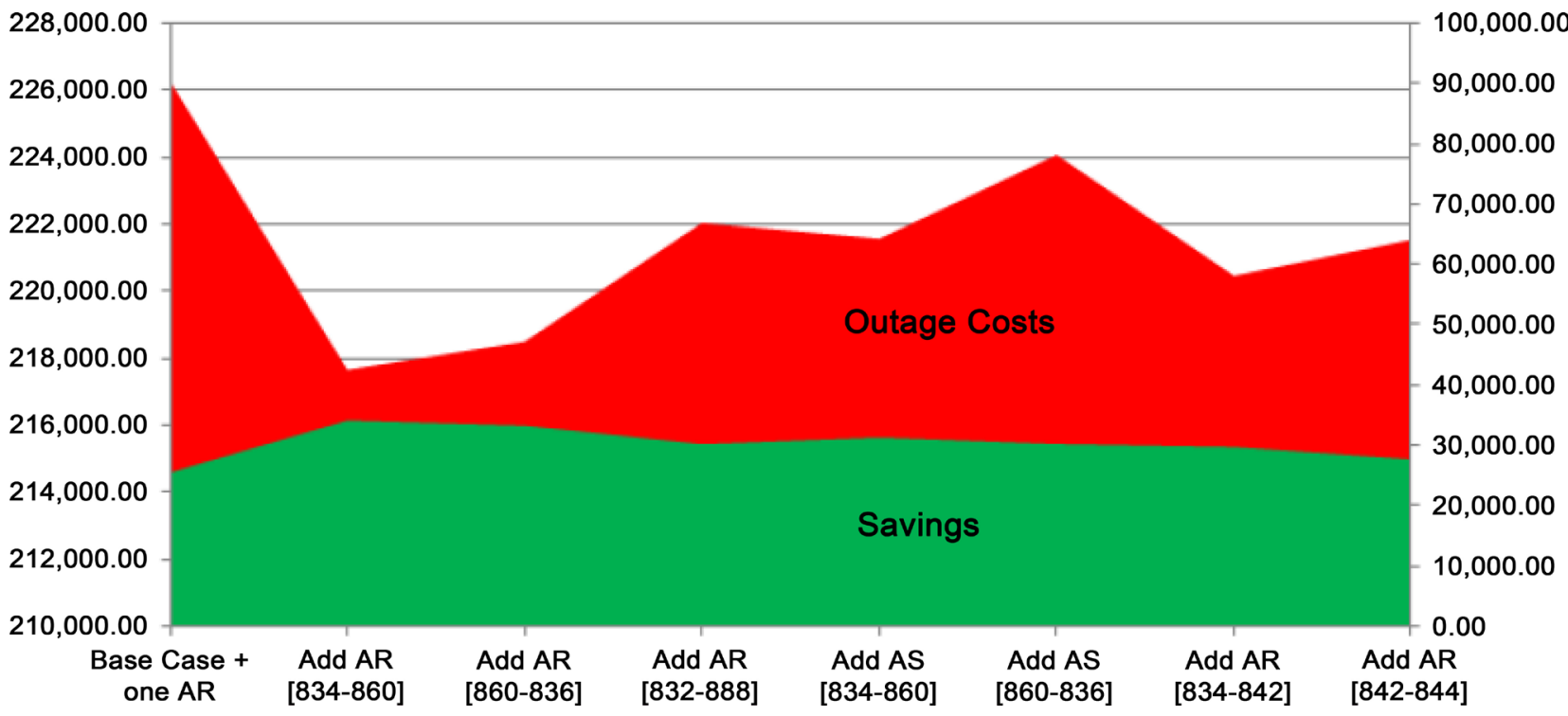

Figure 4. The savings to the outage costs for case study 1. 
by closing the gap with the outage costs.

It is also noted that there are no significant changes applied to CAIDI. This is due to the fact that CAIDI mathematically equals to SAIDI divided by SAIFI, which means that when we have improvements on both SAIDI and SAIFI, these improvements are not going to be reflected in CAIDI unless there are outstanding improvement in SAIDI only. Regard ASAI, it is noted that this index maintains higher reliability values (over 0.99 in all the cases) since the measure here is how much energy an average customer receives to the amount this customer demanded from the utilities. Thus, we can conclude that both CAIDI and ASAI are not good reliability measures as SAIFI and SAIDI.

One of DISREL's virtues is that it can quantify the outage costs for each option based on, EUE, which represents the expected unserved $\mathrm{kW}$ per year due to interruptions. According to [15], the U.S. utilities' losses due to energy not being served to the customer is estimated to be in between $\$ 80$ to $\$ 188$ billion a year, which does not include the damages that might happen to the equipment. The outage cost in this study is assumed to be $\$ 10$ for each $\mathrm{kWh}$ lost, which is reasonable when compared with the real life outage costs that were estimated in reference [16]. The installation of an effective, high-quality automatic recloser costs $\$ 20,000-\$ 30,000$ in total [17] [18]. Thus, it is more likely that this kind of investment will ensure a payback to the electric utility in less than 1.8 years from the installation taking place. However, it is worth mentioning that the return might be sooner than suggested, since the savings in our study are marked for only one distribution feeder, which is only considered as generalized saving values, whereas the local utilities, in most cases, have hundreds of distribution feeders in their electrical infrastructure. Thus, this study should be considered effective in evaluating the impact of this smart-grid concept on the overall distribution system that consists of hundreds of similar radial distribution feeders.

Case Study 2: The Reliability Impact of the Distributed Generators on the

\section{Radial Feeder}

We emphasize in this work that the DG units would considered great tools to enhance the reliability of the distribution grid. Numerous studies have been conducted to evaluate the great potential of connecting DGs on the reliability [19] [20] [21]. At the beginning, we investigate modeling a 1 MW distributed generator, connected to node 890 , where around $30 \%$ of the customers were found. Figure 5 shows the modified test model to include the $1 \mathrm{MW}$ distributed generator. Table 3 shows the results after the modeling of the test system. The base case would be here the modified system shown in Figure 5 above. The results of the base case illustrate the need for the automatic reclosers/CBs when we install a DG to the distribution system; otherwise, there would be no benefit since the fault will certainly block the connection of the DG units during outages.

The DG unit could be sized based on the need, whereas in this feeder, a $1 \mathrm{MW}$ DG unit provides approximately the same benefits that could be added by the installation of a $6 \mathrm{MW}$ for example, since the amount of load connected to the feeder is around 1.7 MW, which would make no sense to connect a DG unit that 


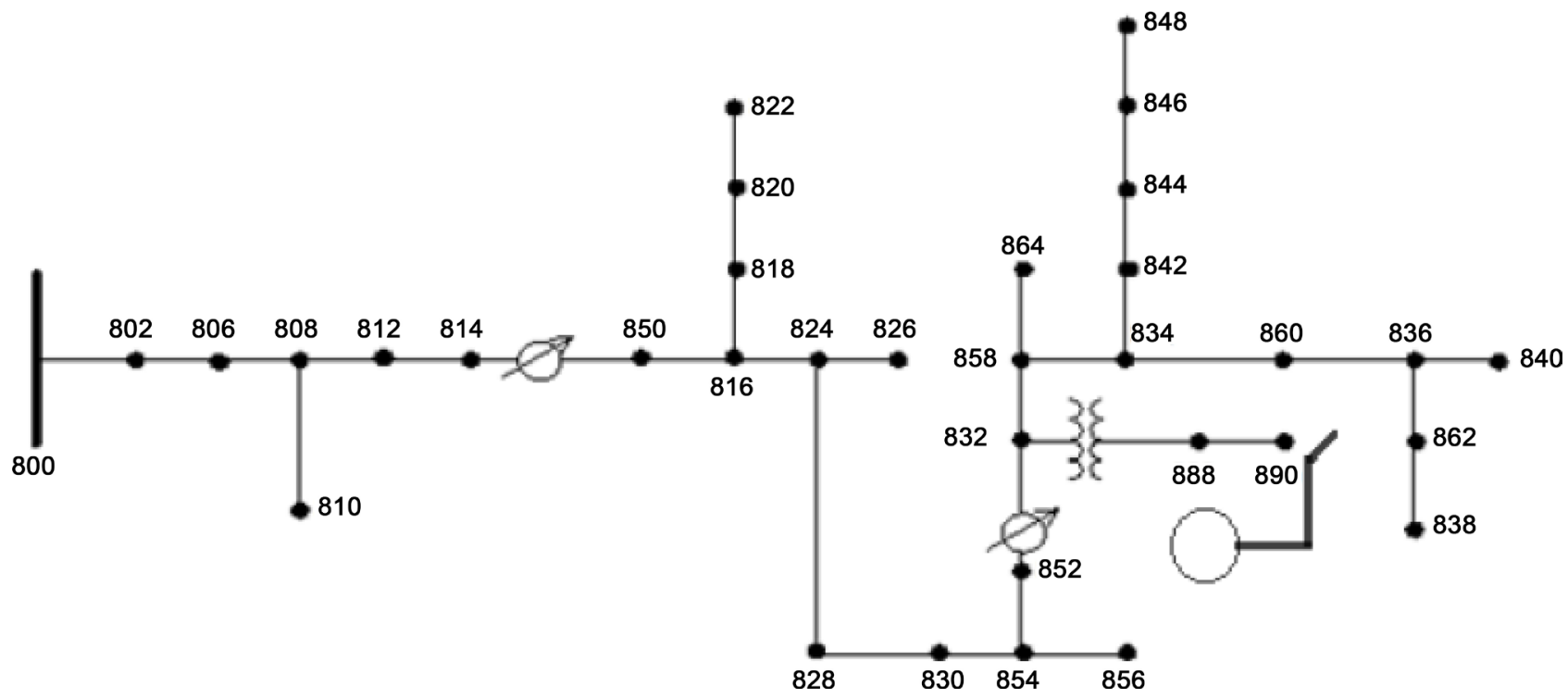

Figure 5. The test feeder with one DG unit connected.

Table 3. Results of the installation of one 1 MW DG unit at node 890.

\begin{tabular}{ccccccc}
\hline Case Description & SAIFI & SAIDI & CAIDI & ASAI & EUE (kW) & Outage Costs (\$) \\
\hline Original Case & 5.35187 & 927.25385 & 173.25789 & 0.998235822 & 25,245 & $251,769.00$ \\
Base Case + one DG & 5.35187 & 764.83942 & 142.91068 & 0.998544812 & 20,840 & $207,732.00$ \\
Add AR [852-832] & 4.24777 & 516.23724 & 121.53123 & 0.999017835 & 14,082 & $140,250.00$ \\
Add AR [854-852] & 4.30945 & 520.5567 & 120.79435 & 0.999009609 & 14,198 & $141,414.00$ \\
Add AR [830-854] & 4.49053 & 546.98199 & 121.80791 & 0.998959303 & 14,913 & $148,562.00$ \\
Add AR [828-830] & 4.6694 & 567.53998 & 121.54451 & 0.998920202 & 15,474 & $154,167.00$ \\
Add AR [888-890] & 4.94313 & 593.51715 & 120.06919 & 0.998887079 & 16,203 & $161,381.00$ \\
Add AS [830-854] & 5.35186 & 644.85278 & 120.49136 & 0.998773098 & 17,576 & $174,718.00$ \\
\hline
\end{tabular}

provides power more than the customers demand. Figure 6 shows the customer minutes per year for the feeder considering 1 MW DG unit at node 890. For the original IEEE 34 node feeder, the estimated interruption minutes per year for the whole feeder are simulated to be 753,000 minutes year. When we considered connecting a DG unit to the system, as shown in Figure 5, the total interruption minutes per year were greatly reduced when considering several scenarios for adding automatic reclosers/or switches. For instance, the installation of one automatic recloser between nodes $852-832$ to the modified system will reduce the interruption minutes to almost 419,000 minutes per year, which is approximately $44.32 \%$ reduction than the original test system (with no DG or AR connected at all). In the case of any contingency event, the DG unit will provide the system the ability to operate as a small microgrid, providing service to the unaffected parts of the feeder and improving the system indices, specifically SAIDI, which will provide huge savings to the involved parties (both the utility and the IPPs) as shown in Table 4.

To better understand the potential effects of adding more DG units in the sys- 


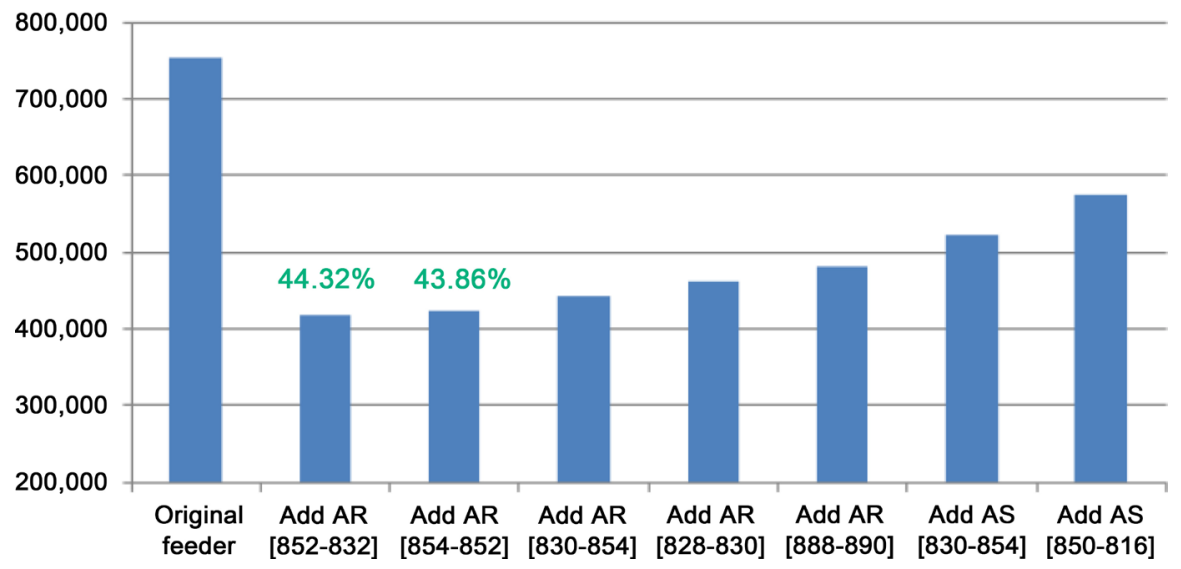

Figure 6. Customer interruption improvements per year for the feeder.

Table 4. The savings in case of connecting $1 \mathrm{MW}$ DG unit to the grid.

\begin{tabular}{cc}
\hline Case Description & Savings (\$) \\
\hline Base Case with DG & $44,037.00$ \\
Add AR [852-832] & $111,519.00$ \\
Add AR [854-852] & $110,355.00$ \\
Add AR [830-854] & $103,207.00$ \\
Add AR [828-830] & $97,602.00$ \\
Add AR [888-890] & $90,388.00$ \\
Add AS [830-854] & $77,051.00$ \\
Add AS [850-816] & $59,996.00$ \\
\hline
\end{tabular}

tem, we model the test feeder after installing three 1-MW DG units at nodes 890 , 844 , and 820 which constitute the most populated nodes in the feeder. Based on the results, when we install an automatic recloser along with the three DG units in the specified location, the system's SAIDI would decrease from $927.25 \mathrm{mi}-$ nutes (obtained in the IEEE original feeder) to 425.52 minutes, which correspond to over $54 \%$ in SAIDI improvements. For SAIFI index, the modified system has reduced the frequency of interruptions from 5.352 to 3.532 per customer, marking a $34 \%$ reduction in SAIFI. However, we noticed again that there is no significant change applied to CAIDI even in the case of the DG, which shows that we cannot consider CAIDI a real measuring for system reliability improvements. Figure 7 shows the savings obtained by installing the three DG units on the distribution feeder. In the case when adding the automatic recloser between $834-842$ or $842-844$, it is projected that the utility will experience the greatest savings among other options, which can be proven by the fact that the system will be able to recon figure in order to maintain service to a substantial number of customers during different outage scenarios. Thus, it is recommended, in case of this feeder only, that one automatic recloser would be enough to achieve the targeted reliability goal, and to isolate a proper portion of the network as a small islanded microgrid during outages, to maintain service to a substantial number 


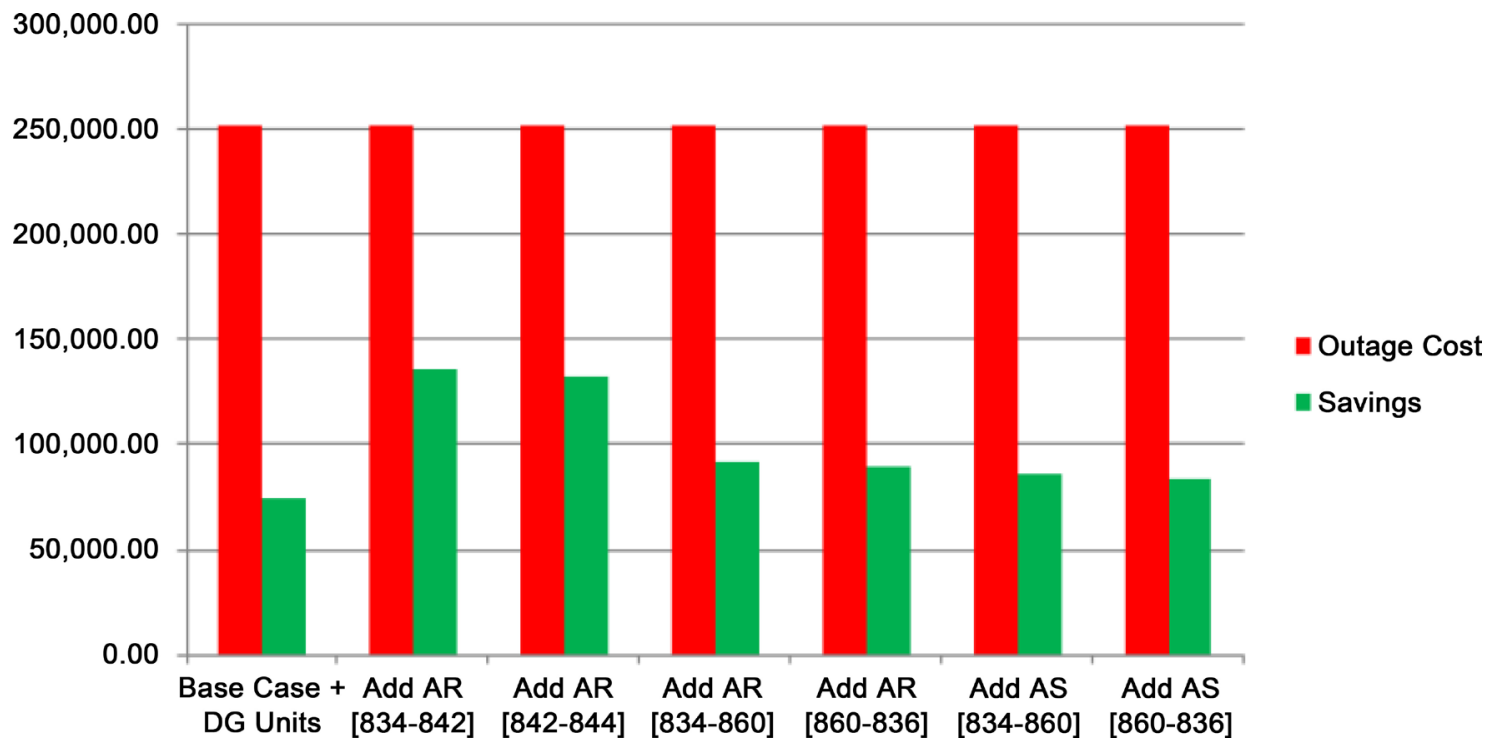

Figure 7. The savings vs outage costs for case 3 considering 3 DG units.

of customers. The reduction in the SAIDI and SAIFI indices when adding multiple reclosers could be attributable to the fact that the DG units have another virtue in improving reliability by taking the form of peak shaving, where the DG units can generate more on-site power than the demand on the feeder, allowing more power to support the grid during normal operation.

\section{Conclusion}

This paper analyzes and examines the effects of smart grid applications on the reliability of power distribution systems. Unlike the generation and transmission sectors, the distribution of power systems did not receive much attention until recent years, where many have emphasized the great potential that can be achieved in this field of the electrical systems. The concept of the smart grid is very broad and difficult to summarize. However, the effects of two main applications of the smart grid have been examined in this work, which are the optimal use of the automatic sectionalizing devices, such as the automatic recloser and the automatic switches, and the accommodation of distributed generation. To reach the goal of this work, several case studies were applied. The results show that the optimal installation of the automatic reclosers will enable the concept of a self-healing power distribution grid that can recover quickly and automatically from major disturbance events, and restore power to as many customers as possible, resulting in significant improvement in the system indices, for instance in SAIDI and SAIFI. This has resulted also in great savings to the power providers, since the utility will be able, using the automatic reclosers and/or switches, to reduce the interruption duration which reduces the expected unserved $\mathrm{kWh}$ to the consumers. In addition, we simulate the effect of the installation of the distributed generators on the system. Results have shown that the DG units can apply the concept of the microgrid, isolating an important portion of the distribution feeder to maintain service to significant numbers of customers. In all, we 
conclude that both the installation of automatic sectionalizing devices and distributed generation units will achieve the concept of a smart grid, providing a more intelligent and reliable power system distribution network.

\section{Acknowledgements}

The authors of this paper want to thank Dr. Sudir Agarwal of General Reliability for all valuable comments and help he provided in this work. We recognize the great virtues of DISREL, the intelligent-based software that was used while conducting this work. For more details on the work presented in this paper, you can review the work presented by Aljohani (2014) in reference [14].

\section{References}

[1] Brown, R.E. (2009) Electric Power Distribution Reliability. 2nd Edition, Marcel Dekker, New York.

[2] United States Department of Energy (2014) Office of Electricity Delivery and Energy Reliability.http://energy.gov/oe/technology-development/smart-grid

[3] Billinton, R. and Allan, R.N. (1996) Reliability Evaluation of Power Systems. 2nd Edition, Plenum Press, New York. https://doi.org/10.1007/978-1-4899-1860-4

[4] Short, T.A. (2004) Electric Power Distribution Handbook. CRC Press, Boca Raton.

[5] Munasinghe, M., Scott, W.G. and Gellerson, M. (1979) The Economics of Power System Reliability and Planning: Theory and Case Study. John Hopkins University Press, Baltimore.

[6] Li, W. (2011) Probabilistic Transmission System Planning. John Wily \& Sons, Inc., Hoboken. https://doi.org/10.1002/9780470932117

[7] Arritt, R.F. and Dungan, R.C. (2011) Distribution System Analysis and Future Smart Grid. IEEE Transactions on Industry Applications, 47, 2343-2350. https://doi.org/10.1109/repcon.2011.5756725

[8] Werner, V., Hall, D., Robinson, R. and Warren, C. (2006) Collecting and Categorizing Information Related to Electric Power Distribution Interruption Events: Data Consistency and Categorization for Benchmarking Surveys. IEEE Transactions on Power Delivery, 21, 480-483. https://doi.org/10.1109/TPWRD.2005.852303

[9] Lasseter, R.H. (2011) Smart Distribution: Coupled Microgrids. Proceedings of the IEEE, 99, 1074-1082. https://doi.org/10.1109/JPROC.2011.2114630

[10] Piagi, P. and Lasseter, R.H. (2006). Autonomous Control of Microgrids. Proceedings of the IEEE Power Engineering Society Meeting, Montreal, Quebec, 8 June 2006, 8. https://doi.org/10.1109/pes.2006.1708993

[11] Zheng, H., Cheng, Y., Gou, B., Frank, D., Bern, A. and Muston, W.E. (2012) Impact of Automatic Switches on Power Distribution Reliability. Electric Power Systems Research, 83, 51-57. https://doi.org/10.1016/j.epsr.2011.08.018

[12] Billinton, R. and Jonnavithula, S. (1996) Optimal Switching Device Placement in Radial Distribution Systems. IEEE Transactions on Power Delivery, 11, 1646-1651. https://doi.org/10.1109/61.517529

[13] Lim, I., Sidhu, T.S., Choi, M.S., Lee, S.J. and Ha, B.N. (2013) An Optimal Composition and Placement of Automatic Switches in DAS. IEEE Transactions on Power Delivery, 28, 1474-1482. https://doi.org/10.1109/tpwrd.2013.2239314

[14] Aljohani, T.M. (2014) Distribution System Reliability Analysis for Smart Grid Applications. ProQuest Dissertations Publishing, Southern California. 
[15] Williams, J (2013) Zero Carbon Homes-A Road Map. Earthscan and Routledge Press, London, 42.

[16] Lawrence Berkeley National Laboratory. Environmental Energy Technologies Division (2003) A Framework and Review of Customer Outage Costs: Integration and Analysis of Electric Utility Outage Cost Surveys. Survey, Lawrence Berkeley National Laboratory, Berkeley.

[17] Chowdhury, A. and Koval, D. (2009) Power Distribution System Reliability: Practical Methods and Applications. John Wiley and Sons, Hoboken. https://doi.org/10.1002/9780470459355

[18] Florida Electric Cooperatives Association (2012) Improving Network Reliability with Reclosers. http://www.feca.com/RecloserTechnology.pdf

[19] Chowdhury, A., Agarwal, S.K. and Koval, D. (2003) Reliability Modeling of Distributed Generators in Conventional Distribution Systems Planning and Analysis. IEEE Transactions on Industry Applications, 39, 1493-1498.

[20] Al-muhaini, M. and Heydt, G. (2013) Evaluating Future Power Distribution System Reliability Modeling Including Distributed Generation. IEEE Transactions on Power Delivery, 28, 2264-2272.

[21] Mozina, C.J. (2013) Impact of Smart Grids and Green Power Generation on Distribution Systems. IEEE Transactions on Industry Applications, 49, 1079-1090.

\section{Nomenclature}

IEEE: Institute of Electrical and Electronics Engineering.

EPRI: Electric Power Research Institute.

SCADA: Supervisory Control and Data Acquisition.

SAIDI: System Average Interruption Duration Index.

SAIFI: System Average Interruption Frequency Index.

CAIDI: Customer Average Interruption Duration Index.

EUE: Expected Un-served Energy.

ASAI: Average Service Availability Index.

RBTS: Reliability Test System.

AMI: Advanced Metering infrastructure.

DG: Distributed Generation.

AR: Automatic Recloser.

AS: Automatic switch.

OD: Outage Duration.

OF: Outage Frequency.

U: Unavailability

A: Availability.

P: Probability of the component to be available.

Q: Probability of the component to be unavailable.

$\lambda$ : Failure rate of an electrical component.

MTTR: Mean Time To Repair.

MTTS: Mean Time To Switch 
Submit or recommend next manuscript to SCIRP and we will provide best service for you:

Accepting pre-submission inquiries through Email, Facebook, LinkedIn, Twitter, etc. A wide selection of journals (inclusive of 9 subjects, more than 200 journals)

Providing 24-hour high-quality service

User-friendly online submission system

Fair and swift peer-review system

Efficient typesetting and proofreading procedure

Display of the result of downloads and visits, as well as the number of cited articles Maximum dissemination of your research work

Submit your manuscript at: http://papersubmission.scirp.org/

Or contact sgre@scirp.org 